\title{
The Concept of Male and Masculinity, as for Adolescents Age 15-18, in the up Northern Region of Albanian Society, a Reflection of the Gender Culture in Albania
}

\author{
Helga Dizdari \\ University of Shkoder 'Luigj Gurakuqi' \\ helga.dizdari@gmail.com
}

\begin{abstract}
One specific component of identity development is gender identity, which refers to the development of a broad set of characteristics that distinguish between men and females and includes personal attributes, social roles, social customs, activities, and behaviors. It is though that during mid-adolescence gender is quite rigid and stereotyped. This study explored the perceptions of young male adolescents on gender roles, masculinity and stereotypes. The results confirmed that the male adolescents aged 15-18, are holders of rigid gender stereotyped roles which match perfectly with those of a masculine society as described by Hofstede (2001). Adolescents at this age (15-18) didn't experienced gender identity crisis, as it might be generally thought.
\end{abstract}

Keywords: gender, identity, masculinity, femininity, stereotypes

\section{Introduction}

For much of Albania country's patriarchal history over the decades, the picture of "Albanian man" has been dominated by the stereotypes of men who are supposed to be assertive, tough, and focused on material success (Hofstede, 2001). Masculinity, certainly as it has been traditionally understood, has become unfashionable and the 'crisis' has been created by a reversal in value of 'male' and 'female' traits. Being very logical, disciplined, rational and competitive are now seen as "not so cool" whereas the very traits which once marked out women as weak and inferior-emotional, spontaneous, intuitive, expressive, compassionate, empathetic-are increasingly seen as the makers of maturity and health" (Clare, 2000, p. 68). For Clare (2000), 'at the heart of the masculinity crisis is the confusion in the reconciliation of the private and the public sphere, the intimate and the impersonal, the emotional and the rational' (2000, p. 212).

Twenty-five years of constant socio-economic transition of Albania have lead on a continuous changing of social policies and realities, family dynamics, a shifting economic development and the surge of women into the workforce and public life. All these factors have affected the concept of and have add colors to the picture of what it means to be a "man in Albania" today.

Adolescence per se is known as the stage of confusion and insecurity, thus a conflictual culture around tends to complicate even more the process of identity maturation. Erikson (1959) in his identity developmental theory stated that the formation of a healthy sense of identity is crucial in transitioning from adolescence to adulthood. This important step in maturing is challenged from many sources such as implicated lifestyle, classroom dynamics, peer interactions, and parental influences, which are directly to be associated with identity development. In addition, public image as transmitted through media services plays a role in determining an adolescent's acceptance of gender roles and expressions (Shaw, Kleiber, \& Caldwell, 1995).

\section{Development of Gender Identity}

One specific component of identity development is the gender identity. Gender identity refers to whether people consider themselves to be primarily masculine, primarily feminine, or some combination of the two (Bem, 1976). Although often used interchangeably, the terms "gender" and "sex" do not refer to the same thing. "Gender" refers a broad set of characteristic 
qualities that distinguish between masculinity and femininity and includes personal attributes, social roles, social customs, activities, and behaviors. These qualities associated with a particular gender vary over time, and across cultures, which is not true for sex. The term "sex" is a constant across time and culture and refers to a biologic, chromosomal determination of being either male $(\mathrm{XY})$ or female $(\mathrm{XX})$. In simplest terms, sex is biological while gender is sociological. During early to mid-adolescence, youths' understanding of gender is quite rigid and stereotyped. As a result, younger adolescents will typically participate in more gender-stereotyped behaviors than do older adolescents. This means that girls will gravitate toward more "girly" activities and present an ultra-feminine appearance, while guys will lean toward more "guy" activities and present a macho-masculine appearance. Usually, stereotypical behaviors are passed down from one generation to the next. When fathers, grandfathers, uncles, older brothers, and friends tell youth what it means "to be a man," or describe what men are expected to do, this shapes youths' perception of masculinity, and influences their behavior and similarly for the girls. It will be their mothers, grandmothers, aunts, older sisters, and friends will tell teen girls what is "lady-like," which will shape girls' perceptions of femininity and influence their behavior. By late adolescence youths' gender identity typically becomes more stable, but without rigidity. At this point youth feel confident and secure enough to enjoy activities that interest them; regardless of whether or not these activities are traditionally associated with their gender.

Because individuals do not have biologically fixed identities, any sense of self can only come about through working to achieve a sense of 'belonging' in the social world. However, 'belonging' is not an automatic process, and so far most men masculine performance is central to achieving entry to, and being accepted within, any particular 'community' of men. This desire for belonging creates, then, both gender and an individual's sense of self. As Bell describes it, "identity is the effect of performance and not vice versa." (Bell, 1999;Butler, 1990) Such understandings do not assume that males are passive in this process of identity work; this is not simply a case of all-powerful gender socialization. Rather, all individuals are skilled at creating themselves, but within the parameters of their social and cultural experience, factors which are also subject to change (Whitehead \& Barrett, 2001).

\section{Male and Masculinity}

Gender identity is considered to be interpersonally and environmentally influenced (Pollack, 1995). Because gender identity is significantly influenced by outer factors, seeking combinations of diverse experiences would provide an adolescent male with the opportunity to explore various roles and in time find himself. According to Josselson (1980, p.12), exploring identities involves both individuation and social relatedness. Individuation refers to the need to separate self from others and social relatedness refers to the need of belonging to a group. Both needs are influenced by the unique gender roles explored by adolescents (Poole, 1986). In relation to both needs, Goodey (1997) discovered that the uniquely male "fearless expression" trait is largely responsible for a male adolescent's denial of vulnerability and the display of aggressive acts toward others. Unfortunately, the popular understanding of 'maleness' is often reduced to that which is not feminine. As a result, Ghaill $(1994$, p.40) concluded that a stable male identity has traditionally fallen into the stereotypes of the strong, rational, and sometimes aggressive man and the traditional contexts usually promote these stereotypes. Boys experimenting with acts of recklessness (denial of vulnerability) or aggression towards others and receive positive responses are more likely to accept this kind of identity (Goodey, 1997). Traditional male stereotypes of dominance, aggression, and lack of emotional expression are present and promoted in most of the every-day social environments but mostly in sports and television. Boys typically spend a significant amount of time in both of these activities; however, they offer little opportunity for gender elaboration with an emphasis on traditional male expression. Because individuals do not have biologically fixed identities, any sense of self can only come about through working to achieve a sense of 'belonging' in the social world. However, 'belonging' is not an automatic process, and so far most men masculine performance is central to achieving entry to, and being accepted within, any particular 'community' of men. This desire for belonging creates, then, both gender and an individual's sense of self (Bell, 1999;Butler, 1990) Such understandings do not assume that males are passive in this process of identity work; all individuals are skilled at creating themselves, but within the parameters of their social and cultural experience, factors which are also subject to a change (Whitehead \& Barrett, 2001).

To conclude, masculinities are a critical part of the gender order and cannot be understood separately from it, or from the femininities which accompany them (Connell, 1995; Giddens, 2001). The authors, Morgan (1992), Sedgwick (1985), Maclnnes (1998), and Cornwall and Lindisfarne (1994) would all agree that masculinity is socially and historically, not biologically, constructed. Capitalism places men in a network of social relations that encourages sets of behavior recognized as masculine. Masculinity is thus viewed as a set of practices into which individual men are inserted with reference to 
upbringing, family, area, work and sub-cultural influences. Socio-economic positioning profoundly impacts the masculine sense of self so much so that men's identities are constructed through social structures which exist over and above any actions of the individual (Edley \& Wetherell 1995). Anyways, a good point with which to start a study on masculinity is Morgan's (1992) assertion that what is considered masculinity and femininity in a certain culture can be best approached if studied from the stand point of what men and women do, that is, how they behave and what they are. If gender is cultural, then it follows that women as well as men can step into and inhabit masculinity as a 'cultural space', one with its own sets of behaviors. In this view 'the masculine' and 'the feminine' signify a range of culturally defined characteristics assignable to both men and women (Beynon, 2002).

\section{Study objectives}

Up to this date no or little research has been devoted to the study of masculinity among adolescents in the up northern region of Albania who are facing gender identity maturation. Insights into the issues of gender roles, stereotypes and masculinity could help on understanding better what is happening with the inner world of the male adolescents in nowadays Albanian society and how could be helped to maturate healthier gender identities.

The overall aim of this study, was:

- To conduct a qualitative study on perceptions of adolescent young males (15-18) on gender and expected masculine and feminine roles in the up northern Albanian society, mainly in the private sphere, paying particular attention to the relation of masculinity, femininity, stereotypes and gender role issues.

- To gather quantitative data and obtain information regarding attitudes and perceptions of young men towards gender roles and masculinities.

\section{Participants and Procedures}

Participants for this study were a convenience sample of high school aged boys currently enrolled in 4 public high schools of the city of Shkoder. The potential participants were informed the study and were asked to secure parental permission to consent participation. There were a total of 30 participants. The range of ages was 15 to 18 years, with an average age of 16.7 years (refer to table 1.).

Table.1.

Statistics

\begin{tabular}{|ll|l|}
\hline Age & & \\
\hline N & Valid & 30 \\
& Missing & 0 \\
Mean & & 16.7667 \\
Median & & 17.0000 \\
Mode & 17.00 \\
Range & 3.00 \\
Minimum & & 15.00 \\
Maximum & & 18.00 \\
\hline
\end{tabular}

The sample was somewhat diverse with respect to location where they were coming from; city and villages around, academic achievements, and number of family members. Participants were interviewed individually by the first author. The individual interviews lasted approximately 20 minutes. Generally speaking, the interview questions were designed to tap into the constructs represented within gender roles and stereotypes typical for masculine societies as referred to Hofstede (2001). As suggested by Patton (2002), the semi-structured interview guide used open-ended, non-leading questions in order to integrate the respondents in the interview process. The interview guide addressed topics such as what does it 
mean to be a man or a women in the Albanian society, differences between boys and girls, households, and family responsibilities. Tapes of the interviews were transcribed and used for coding.

\section{Data analyses and Presentation}

Interview data was analyzed with the content analysis method (Neuendorf, 2010). Each transcript was divided into meaning units which were used as codes, representing the key concepts and topics of respective text fragment (Tesch, 1990). As a starting point, the participants' interview responses were placed into broad themes, each with a label reflecting the content. Subsequently formal coding occurred and individual text units were assigned to subthemes within the broader topic areas. The formal coding was not a linear process as the data was repeatedly reassigned to new categories, and the labeling system was revised several times in order to represent the participants $\square$ responses most suitably. In line with Patton (2002) the researchers followed the principle of internal homogeneity, ensuring that different text units in a category fitted together in meaningful ways. This method of data presentation corresponds to the realist approach (Sparkes, 2002) which suggests the use of participants $\square$ words to exemplify their experiences and perceptions, an approach that is followed by various researchers in the field (e.g. Tod et al., 2009; Tod et al., 2011).

Research credibility. According to Patton (2002) triangulation provides credibility to qualitative research analysis. The present study design included data source triangulation as two independent researchers collected relevant information via interviews. Consensus regarding the interpretation of meaning units as well as the organization and labeling of emerged themes and categories was reached through extensive discussion by the researchers. Since there are multiple ways to interpret qualitative data (Smith, 2003), graphic depictions of the hierarchical structure of the emerged themes will be provided in the following.

\section{Results}

Interview data units were analyzed and arranged into themes describing perceptions of adolescent young males on gender, and expected masculine and feminine roles, stereotypes and gender role conflicts. The following three themes emerged from the data analysis process: (1) gender identity, (2) stereotypes, (3) gender roles.

\section{Gender Identity}

Table 2. shows the categories that emerged from the interviews related to the sources of gender identity, being a male in respect to being a female. Categories of the respective theme comprise (1) physical attributes, (2) psychological attributes, (3) both, physical and psychological attributes and (4) social attributes.

\author{
Category: Physical Attribution \\ (being beautiful for girls and strong for boys)
}

\section{Category: Psychological Attribution}

(being mentally tough for boys and emotinally vulnerable for girls)

Theme: Gender Identity

Category: Both (Physical+Psychological Changes)

\section{Category: Social Attribution}

(Boys and girls are different due to different ways of upbringing them. Culture+Mentality)

Table.2

Physical attributes: This category outlines the fact that changes between males and females are based mainly on physical and biological differences. Gender identity in here is perceived as having a male strong body and a female sensitive body. About $90 \%$ of the participants declare that the main differences between males and females stands on body strength, sensitivity and beauty. 
Respondent 12: "Boys are different from girls regarding emotional and physical issues. Boys are stronger outside but weaker inside."

Respondent 13: "Boys are stronger then girls and can do works that girls can not do."

Respondent 20: "Boys are strong while girls are beautiful."

Respondent 29: "Boys are brave and like to be dominant."

Psychological attributes: Except the physical differences, most of the participants see also the differences between genders on psychological constructs such as emotional and behavioral development. The behavior in this case is seen as the outer expression of what the individuals feel inside them. The respondents perceive gender identity on terms of feeling and behaving like a male or a female. Most of them say that women are more emotionally sensitive than men, thus confirming the traditional stereotypes of the strong man who holds the emotions per se.

Respondent 2: "They differ mentally and physically, where boys are superior and girls are more emotional and empathetic."

Respondent 6: "They change mainly regarding psychological issues such as girls like to flirt and know how to do it."

Respondent 11: "Boys are stronger physically and emotionally, while girls are beautiful, emotional and like to gossip."

Both, physical and psychological attributes: Most of the respondents agreed that males and females differ in terms of physical and psychological issues and therefore gender identity is formed as a complex of physical changes and psychological ways of feeling and expressing them.

Respondent 12: "Boys differ from girls both in the physical and emotional aspects. Boys are strong outside, but week inside and vice-versa."

Social attributes: A majority of participants declare that the changes are mainly due to the different expectations the society has set forward for boys and girls. Hence, the girls and the boys have same predisposition on maturing a personal identity but it is the mentality who limits them, especially the girls. Thus the changes on gender identity are perceived to be strongly affected by the cultural norms and values about sexes.

Respondent 18: "They change by the way mainly the mentality affects them. Bous should be strong and authoritative, while girls should be closed and humble".

Respondent 23: "They change by the roles and responsabilities they share in life."

Respondent 5: "They change by the way they grow up. Girls are more closed and boys are more open and free."

\section{Stereotypes}

Table 3. describes the categories that emerged from the interviews related to the sources of stereotypes, what does it mean to be a male in respect to being a female in the Albanian society, what are the expectations the both genders should fulfill. Categories of the respective theme comprise (1) characteristics of Albanian males, (2) characteristics of Albanian females.

\section{Theme: Stereotypes}

Category: Albanian Male Characteristics

(strong, decisive, hard-working, traditional mentality)

\section{Category: Albanian Female Characteristics}

( Beautiful, good girl, sincere, be a good household, modest)

Table 3. 
Characteristics of Albanian males: Albanian males are perceived in different spheres, at personal level and family and social level. At personal level they are described in terms of personality, character and other behavior issues.

Respondent 2: "Respectable, likes to work, prejudices and keep the word promised.'

Respondent 8: "Strong, violent, prejudices and doesn't face his emotions."

Respondent 16: "Strong, to the point and decisive."

Whereas, at family and social relationships level, they are perceived as mainly responsible for the maintenance of the house, thus relating it to the socio-economic power both within the family and the society in general.

Respondent 5: "She should take care of the kids, respect my mom, while I provide economically for the family."

Respondent 18: "The responsabilities should be shared but she has to take more responsabilities taking the family.'

Respondent 23: "The man should provide to the family, while the woman should take care for the kids."

Characteristics of Albanian females: According to the participants, girls and females should be mainly responsible for the house holds and the education of the kids. They are seen in the framework of the relationships with others and lots of their behaviors are translated into a moral code, that women should not have lots of relationships, should not spent too much time on internet and should not be exaggerated. Usually, they associated with positive expectations that they should mostly fulfill.

Respondent 6: "Calm,simple, learns fast, listen the parents advice, doesn't do bad things"

Respondent 9: "smiley, knows how to take care of the kids in all the aspects, lovely."

Respondent 10: "Sincere, not-lazy and helps others."

Respondent 12: "Positive personality, sincere and good behaviour."

Respondent 13: "Respectable, humble and not outgoing."

Respondent 14: "Smart, smiley, beautfiful, shoul understand each-other and share responsabilities."

\section{Gender Roles}

Gender roles, refer to the expectations a society has in relation to boys and girls. Their behavior into the society is considered proper if it meets the gender standards of that society. Thus figure 3 will consider the following three themes: (1) expectations for boys (2) expectations for girls (3) responsibilities within the family. 


\section{Category: Responsability within the family}

( both should have responsabilities within the family, but girls are mainly responsible for the households and the upbringing of the kids, whereas the man should provide resources for the family)

\section{Theme: Gender Roles}

\section{Category: Expectations for Boys}

(be respectful, be strong, be responsible for the economic situation of the family)

\section{Category: Expectations for Girls}

(be good wives, take care of the households, careful and loving towards others)

Table 4.

Expectation for boys: In our society the expectation for boys goes in line with the gender stereotypes about males. Most of these expectations are seen in the perspective of physical dominance and the direct responsibility for the economic sustainability of the house but also connected to the honor, a main theme in the Albanian society. Their contribution is seen out of the house.

Respondent 3: "Simple guy with no bad habits'

Respondent 10: "A guy who helps the family, doesn't bother the parents and respects them."

Respondent 13:" Respectable and helps others."

Respondent 11.: "Trustworthy and dedicates himself to work and family."

Respondent 20: "Able to provide the family everything they need.'

Respondent 30: "Trustworthy and takes the importand decisions within the family."

Expectations for girls: Again the expectations of the girls go in line with the stereotypes about the females in the Albanian society. Thus, as mentioned before, girls are mostly seen as connected to somebody else and take value within the framework of relationships. More specifically, their place is seen to be inside the house.

Respondent: 14: "She has to have the university, take care of the house and children and respects my parents"

Respondent 15: "We have to have same or less personalities, she takes care of herself and does the households

Respondent18: "She has to take care of the family but with my help and other members help and should also work outside ( have a career)."

Respondent 19: "She has to obey at me and take care of me after work"

Respondent24: "She has to be a correct person, sincere, likes to do the house chores and loves my mom"

Respondent29: "She has to obey at me and be sincere." 


\section{Discussion and integration of theories}

This work was an attempt to explore perceptions of adolescent young males on gender, sex, on expected masculine and feminine roles, stereotypes and gender roles. The following three themes of (1) gender identity, (2) stereotypes and (3) gender roles that emerged from the data analysis confirmed the reciprocal inter-relation of these three concepts together. Participants acknowledged and gave a broader spectrum of what does it mean to be a male and a female in the Albanian society according to them and that this process is never finished and operates in a continuum. Therefore, identity is understood as always in process, never finally accomplished. So in this regard, there is no core, grounded, or fixed self, but rather a fluid arrangement of multiple subject positions which together provide the means by which the individual achieves a sense of identity (Rajchman, 1995). The importance of masculinity to this process of identity work is in the validation it can give to this fluid self. So if we accept there is no core self, then socially dominant forms of being a male (masculinities) can be seen to provide an acceptable means by which boys and men may express their gender and thus their sense of identity. In taking up these localized and culturally specific signifying practices, males achieve an association with other males and also a differentiation from the 'Other' not only women but also those males who appear 'different'. The difference is usually marked by sexual orientation, but can also include forms of embodiment and ethnicity, as well as national and cultural variations of masculine performance (Whitehead \& Barrett, 2001). What can we see from the results of our study is that the adolescents have taken a stand position in relation to gender roles and stereotypes that confirm those of a traditional masculine trait society such as the Albanian society (Hofstede, 2002). It was not perceived anywhere any gender identity crisis among the participants and maybe that is connected to the fact that Albania society is still a rigid society where gender roles are clearly divided and probably the gender identity crisis has still to arrive. Most of the adolescents were students at the high school and their social life was mainly limited between school and family. In the Albanian society, due to rapid socio economic movements the concepts of masculinity, certainly as it has been traditionally understood, is being constantly challenged thus creating gender identity 'crisis' especially in males, but which has not been confirmed in our study of adolescents males.

\section{Conclusions}

This study investigated and tried to explore the perceptions of young adolescents male in relation to gender roles, stereotypes and masculinity in the northern region of Albania. The results confirmed and were in line with what is generally believed to be a man in a masculine society as described by Hofstede (2001, p. 297);

"Masculinity stands for a society in which social gender roles are clearly distinct: Men are supposed to be assertive, tough, and focused on material success; women are supposed to be more modest, tender, and concerned with the quality of life."

On the other hand, while talking about gender theories, the concept of gender identity conflict or crisis is one of the main issues discussed but such a topic didn't arise among the themes. This should be explored in another study, where either participants are at older age, when the identity has already taken form or should be a specific topic of exploration per se. This study, is a base-line study and gives an overview about main gender stereotypes about boys and girls in Albania, as perceived by boys. Another study like this will take form, but with respondents only girls. It could be of a specific interest how gender roles and traits of masculinity and femininity are perceived by girls and how they differ from those of the boys. Knowing the way young adolescents think about gender, identity and gender relationships may be a great help of educational specialists to reframe programs that help adolescents build healthy gender identities.

\section{References}

[1] Bem, S. L. (1976). "Sex typing and androgyny: Further explorations of the expressive domain". Journal of Personality and Social Psychology, 34, 1016.

[2] Bell, V. (1999). Performativity and Belonging: An Introduction. Theory, Culture and Society, 16(2), 1-10.

[3] Beynon, J. (2002). Issues in Cultural and Media Studies, Masculinities and Culture. Buckingham: Open University Press

[4] Butler, J. (1990). Gender trouble.Feminism and the Subversion of Identity. New York: Routledge.

[5] Clare, A. (2000). On Men: Masculinity in crisis. London: Chatto and Windus. 
[6] Crosnoe, R., Erickson, K.G., \& Dornbusch, S.M., (2002). Protective functions of family relationships and school factors on the deviant behavior of adolescent boys and girls. Youth and Society, 33, 4, 515-544.

[7] Connell, R.W. (1995). Masculinities. Cambridge: Polity.

[8] Cornwall, A. and Lindisfarne, N. (1994).Dislocating Masculinity: Comparative Ethnographies. London: Routledge.

[9] Erikson, E. (1959). Identity and the life cycle: Selected papers. Psychological Issues, 1(1), 5-165.

[10] Ghaill, M. (1994). The making of men. Buckingham: Open University Press.

[11] Giddens, A. (2001). Sociology (4th ed). Cambridge: Polity.

[12] Goodey, J. (1997). Boys don't cry. The British Journal of Criminology, 37, 401-419.

[13] Hofstede, G. (2001). Culture's consequences: Comparing values, behaviors and organizations across nation $\left(2^{\text {nd }}\right.$ ed.) Thousand Oaks, CA: SAGE Publications.

[14] Josselson, R. (1980). Ego development in adolescence. In J.Adelson (Ed.), Handbook of adolescent psychology (pp.188-210). New York: Wiley.

[15] Lindsfarne, N. (1994). Variant masculinities and variant virginities: Rithinking "Honor and Shame". In Dislocating Masculinity: Comparative Ethnographies. London: Routledge.

[16] Morgan, D.H.G. (1992). Discovering Men. London: Routledge.

[17] Neuendorf, K. A. (2010). The content analysis guidebook (9th ed.). Thousand Oaks, CA: SAGE Publications.

[18] Patton, M. Q. (2002). Qualitative research and evaluation methods (3rd ed.). Thousand Oaks, CA: SAGE Publications.

[19] Pollack, William. (1995) Deconstructing Dis-identification: Rethinking psychoanalytic Concepts of male development. Psychoanalysis and Psychotherapy. 12, 30-45.

[20] Poole, M. (1986). Adolescent leisure activities: Social class, sex and ethnic differences. Australian, Journal of Social Issues, 21 (1), $42-56$.

[21] Rajchman, J. (1995). The Identity in Question. New York: Routledge.

[22] Sager, P.S., (1985). Between men: English literature and male homosocial desire. Cooperative Literature, 100, 1139-1144.

[23] Shaw, S. (1988). Gender differences in the definition and perception of household labor. Family Relations, 37, 333-337.

[24] Shaw, S., Kleiber, D., \& Caldwell, L. (1995). Leisure and identity formation in male and female adolescents: A preliminary examination. Journal of Leisure Research, 27, 245-267.

[25] Smith, J. A. (Ed.) (2003). Qualitative psychology: A practical guide to research methods. Thousand Oaks, CA: SAGE Publications.

[26] Sparkes, A. C. (2002). Telling tales in sport and physical activity: A qualitative journey. Champaign, IL: Human Kinetics.

[27] Tesch, R. (1990). Qualitative research analyses types and software tools. New York: Falmer Press.

[28] Tod, D., Andersen, M. B., \& Marchant, D. B. (2009). A longitudinal examination of neophyte applied sport psychologists' development. Journal of Applied Sport Psychology, 21(1), 1- 16.

[29] Whitehead, S. M. and Barrett, F. J. (2001). The Masculinities Reader. Cambridge: Polity. 
